\title{
Free Vibration Analysis of circular plates with holes and cutouts
}

\author{
Shrikant B. Thakare ${ }^{1}$, Prof. A. V. Damale ${ }^{2}$ \\ ${ }^{1}$ (PG Student, Department of mechanical Engg, SRES COE, University of Pune, Maharashtra, India) \\ 2 (Asst. Professor, Department of mechanical Engg, SRES COE, University of Pune, Maharashtra, India)
}

\begin{abstract}
Circular plates with holes are extensively used in mechanical components. The existence of a hole in a circular plate results in a significant change in the natural frequencies and mode shapes of the structure. Especially if the hole is located eccentrically, the vibration behavior of these structures is expected to deviate significantly from that of a plate with a concentric hole. These holes usually cause the change of natural frequency as well as the decrease of load carrying capacity. It is important to comprehend the associated effects in the work of mechanical design or flight control of the structure. Therefore, in this study, an experimental method to determine the modal characteristics of a plate with multiple holes and slots are used is verified by the finite element analysis (FEA) with ANSYS. Also, the relationship between parameter variations and vibration modes is investigated. These results can be used as guidance for the modal analysis and damage detection of a circular plate with a hole.

Keywords: circular plate, FEA, modal analysis, natural frequencies, vibration.
\end{abstract}

\section{Introduction}

The Circular plates with multiple circular holes are widely used in engineering structures, e.g. missiles, aircraft, etc., either to reduce the weight of the structure, to increase the range of inspection or to satisfy other engineering applications. These holes in a structure usually invoke natural frequency change and loading capacity decrease. It is important to comprehend the corresponding effects in the process of mechanical design.

As quoted by Leissa and Narita'"The free vibrations of circular plates have been of practical and academic interest for at least a century and a half", over the past few decades, most of the researches have focused on the analytical solutions for natural frequencies of the circular or annular plates.

Circular and annular plates with variable thickness are widely used in many engineering structures and machines. By appropriate variation of plate thickness, these plates can have significantly greater efficiency for vibration as compared to the plates of uniform thickness and also provide the advantage of reduction in weight and size.

The objective of current work is study of the behavior of circular plates with free boundary condition but having different working conditions such as numbers of holes, aspect ratio, and effect of radial slots/cutouts and with diff thickness of plate is important, as used in several machine components, such as circular saw blades, Disc brake plates, Diaphragm springs etc. The knowledge of natural frequencies of component is of great interest in the analysis of response of structures to various excitations. Unwanted noise, vibration \& accidental failure associated with the operation has become an important economic and technological problem in the industry that can be studied by this work.

ANSYS/CAE is a general purpose finite element analysis tool with a group of engineering simulation programs capable of modelling structures under different loading conditions. It can solve problems of relatively simple structural analysis to the most complicated linear to nonlinear analyses. In a nonlinear analysis ANSYS/CAE automatically chooses appropriate load increments and convergence tolerances and continually adjusts them during the analysis to ensure that an accurate solution is obtained. ANSYS /CAE consist of a widespread library of elements, wherein any type of geometry can be modelled. Apart from solving structural problems, it can also solve problems in other different areas like fracture mechanics, soil mechanics, static analysis, piezoelectric analysis, coupled thermal-electrical analyses, heat problems, and acoustics etc.

\section{Review Of Literature}

Many researchers have studied the vibration of annular plates over a long period of time. Dynamic characteristics of annular plates are of considerable importance in many designs. Circular plates with cutouts are extensively used in mechanical structures. Vibration analysis of this kind of structure is the foundation for structural parameter identification, damage detection and vibration control. In general, most research work has focused on vibration analysis of circular plates with a central hole, i.e., annular plates, and has led to a rapid development of analytical or experimental methods, such as the energy approach, the mode subtraction approach, etc.

Early studies have been reviewed by Leissa. [1] The monograph contains a detailed review of the investigations on the vibration of plates of various shapes, including circular and elliptical planforms. In 
subsequent articles, Leissa provides information on plate vibration including different complicating effects. Although there are many papers on the vibration of elliptical and circular plates, they refer mainly to isotropic and polar orthotropic material.

L. Cheng et.al. [2] Attempts to reveal the relationship between parameter variations (eccentricity, hole size, boundary condition) and vibration modes, and to discover the vibration behavior around the eccentric hole. To our knowledge, these results are new and give guidance for the modal analysis and damage detection and the effects of the eccentricity, whole size and boundary conditions on DMSs are investigated systematically.

Weisensel G. N. [3] has discussed the results of an extensive literature search and review of available sources of numerical natural frequency information for stationary circular and annular elastic plates. In addition to source information is given regarding the specific plate theory, boundary conditions, geometric properties and material properties used to determine the natural frequency information Sources of information are tabulated according to the above parameters for easy reference and selection of desired information This information may be particularly useful to experts and designers when frequency data are required without the need for detailed analysis.

Wook Kang et.al. [4] in their work, attempts were made to derive the explicit closed form solution to mode shapes and its natural frequencies with rather good accuracy. For circular plate such as tree disk, the simply supported and clamped boundary conditions are practically rather difficult for realization compared to completely free ones. Therefore, this study deals only with completely free cases. It will explore the feasibility of direct identification of elastic constants of both polar orthotropic and isotropic plates. The result from this study can be used for parametric studies for dynamic behaviors and nondestructive material evaluation during the initial design process.

Z.H. Zhou et.al. [5] In the present study the symplectic expansion is used to obtain the natural modes of the Kirchhoff circular and annular plates. With the aid of Hamiltonian principle of mixed energy, a set of Hamiltonian dual equations are obtained. The differential eigenvalue problem is then solved using the separation of variables. The solution is expanded in terms of the symplectic adjoint orthogonal Eigen solutions with coefficients to be determined by the boundary conditions. Numerical comparisons to the classical solutions in literature are presented to validate the efficiency and accuracy of the symplectic method. The natural frequencies are calculated for these plates with all possible combinations of free, clamped and simply supported boundary conditions and inner-to-outer radius ratios. These results can be used to validate the accuracy of other numerical method as benchmark values.

\section{Finite Element Analysis (Fea) Technique Using Ansys/Cae}

ANSYS/CAE is a general purpose finite element analysis tool with a group of engineering simulation programs capable of modelling structures under different loading conditions. It can solve problems of relatively simple structural analysis to the most complicated linear to nonlinear analyses. In a nonlinear analysis ANSYS/CAE automatically chooses appropriate load increments and convergence tolerances and continually adjusts them during the analysis to ensure that an accurate solution is obtained. ANSYS /CAE consist of a widespread library of elements, wherein any type of geometry can be modelled. Apart from solving structural problems, it can also solve problems in other different areas like fracture mechanics, soil mechanics, static analysis, piezoelectric analysis, coupled thermal-electrical analyses, heat problems, and acoustics etc. In this analytical framework, ANSYS /CAE is used for evaluating the frequencies, displacements and mode shapes of the model of a cracked plate to investigate the theoretical predictions. The required inputs for the ANSYS /CAE finite element analysis consists of model geometry, material properties, loading, boundary conditions, and an initial crack configuration.

\subsection{Theoretical analysis -}

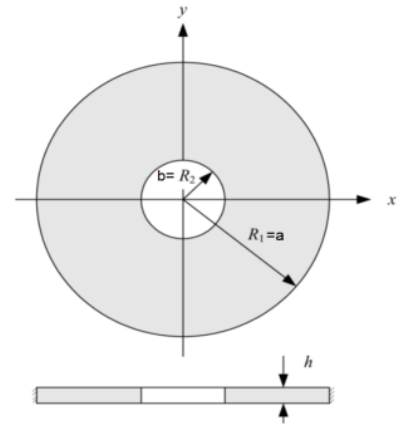

Fig. 3.1.1 circular plate with uniform thickness 
Rayleigh or Love is perhaps the best prime sources for the governing equations and the correct forms of all the boundary conditions. These references are cited by Southwell but later authors consider the equations as common knowledge. The differential equation in polar coordinates, $\{\mathrm{r}, \theta\}$, governing the axial displacement of the plate, $w$, is

$$
D \nabla^{4} w+\rho \frac{\partial^{2} w}{\partial t^{2}}=0
$$

Which when written in extenso becomes:

$$
D\left(\frac{\partial^{2}}{\partial r^{2}}+\frac{1}{r} \frac{\partial}{\partial r}+\frac{1}{r^{2}} \frac{\partial^{2}}{\partial r^{2}}\right)^{2} w+\rho \frac{\partial^{2} w}{\partial t^{2}}=0
$$

Where, $\mathrm{t}=$ time,

$\rho=$ density of the plate material;

$\mathrm{w}=$ plate displacement;

$D=\frac{E h^{2}}{3(1-v)}$

$\mathrm{E}=$ Young's modulus,

: Which might be called flexural rigidity;

$v=$ Poisson's ratio and with

$2 \mathrm{~h}=$ the thickness of the plate (so $\mathrm{h}$ is the half thickness)

The boundary conditions (Rayleigh,) are

For zero displacement: $\mathrm{w}=0 \ldots 2 \mathrm{a}$

For encastred edge, i.e., with zero slope of the plate: $\partial \mathrm{w} / \partial \mathrm{r}=0 \ldots 2 \mathrm{~b}$

A vibrating solution is assumed with displacement varying sinusoidally with azimuth.

Set

$$
w=W \sin (n \theta) \sin (\omega t)
$$

Where $\omega$ is natural frequency.

This separation of variables leads to

$$
\left(\frac{\partial^{2}}{\partial r^{2}}+\frac{1}{r} \frac{\partial}{\partial r}-\frac{\omega^{2}}{r^{2}}\right) W-\beta^{4} W=0
$$

With

$$
\beta^{4}=\frac{3\left(1-v^{2}\right) \rho \omega^{2}}{E h^{2}}=\frac{\rho \omega}{D}
$$

W. T. Norris and J. E. T. Penny have given values of $(\beta a)^{2}$ for various ratios of outer radius to inner radius and different mode characteristics. First six harmonics are given in order for aspect ratio $(b / a=0.1)$.

$(\beta a)^{2}$ Is non-dimensional frequency parameter used to calculate natural frequencies of circular plate.

$$
(\beta a)^{2}=\omega a^{2} \sqrt{\frac{3 \rho\left(1-v^{2}\right)}{E h^{2}}}
$$

Where,

\subsection{Modal Analysis:}

$$
\begin{aligned}
& \mathrm{h}=\text { half thickness in } \mathrm{mm} \\
& \mathrm{E}=\text { Young's modulus } \mathrm{N} / \mathrm{m} 2 \\
& \rho=\text { Density of the cutter material in } \mathrm{kg} / \mathrm{m} 3 \\
& \omega=\text { frequency in rad } / \mathrm{s} . \\
& v=\text { Poisson's ratio taken as } 0.3 \\
& \mathrm{a}=\text { Outer radius of cutter in } \mathrm{mm}
\end{aligned}
$$

Same set of command is used for modal analysis that used in any other type of finite element analysis. Likewise, choose similar option from the graphical user interface (GUI) to build and solve models. Modal analysis determines the vibration characteristics (natural frequencies and mode shapes) of a structure or machine components. Experimental modal analysis of a system, deals with determination of natural frequencies, damping 
ratios, and mode shapes through the vibration testing. In the case of forced vibration, the analysis includes the study of acceleration, velocity and displacement responses of the systems.

Modal analysis is the identification of vibration characteristics of elastic structures. It consists of describing a system by its modal parameters; natural frequencies, natural damping and natural modes. This study enables better understanding of the vibration phenomenon encountered in engineering; its purpose is to get data from experiment in order to determine system characteristics. One can use the data in several ways, depending on the aims to reach.

A reason to make measurements on a real test structure is the need to compare the experimental vibration with the data produced by a simulation program like a FEM program, for instance. The aim is the validation of theoretical model before its further use, with more; complex excitation like shocks or step changes.

Another way of using the information provided by modal analysis is to obtain a frequency response function (FRF) from the theoretical model and real test structure and to compare both results this comparison allows, correcting the model to a certain extent by using a trial and error approach. Modal analysis can be used to quantitatively describe a mechanical element that will have to be part of bigger assembly. Accurate data is required for natural frequencies, damping and mode shapes. This is referred to as a sub structuring process and is in theoretical analysis of complex structures. This method can also be used to predict the vibration behavior of a machinery element that has to be modified for any reason including the one of modifying the vibration properties themselves by reducing the amplitude of vibration at a given frequency or by shifting the resonance frequency of a given mode. Another application for modal testing is that of force determination. Given a theoretical model and measured vibration on a real structure, it is possible to determine the forces that act upon the real structure. Nevertheless this method is very sensitive to modeling inaccuracies and little errors can have huge consequences. Accurate Modal Analysis requires understanding of the theoretical basis of vibration, accurate measurement of vibration, careful and detailed data analysis.

\subsubsection{Steps of Modal Analysis:}

\section{Modeling}

Modeling includes the making of model geometry or to import the geometry from another software package in the working environment.

\section{Model meshing}

This step includes the job name and analysis title and then defines the element types, element real constant, material properties, and the model geometry.

\section{Loadings}

In this step, define analysis types and options, apply load, and satisfy load step options to get the finite element solution for the natural frequency.

\section{Expansion of the modes}

Specify the number of mode that, you have to expand. If frequency range is selected, only modes within that range mode results are appeared.

\section{Results}

Results from modal analysis are written to the structural results file. Results consist of natural frequency, mode shapes relative stress and force distribution. Those results wish to see, database must contain the same modal for which the solution was calculated.

\section{Observations And Fea Analysis}

The specimens of circular annular plate of S.S. are chosen for testing. Following are the material properties for the specimen plates. Young's modulus $(E)=2.1$ X $1011 \mathrm{~N} / \mathrm{m} 2$, Poisson's ratio $(\mu)=0.3$, Density of material $(\rho)=7850 \mathrm{~N} / \mathrm{m} 3$. The structure is axi-symmetric and formed of an isotropic homogeneous elastic material. Three dimensional parameters represent the disk's inner radius (b), outer radius (a) and thickness (h) respectively. Specimens with variable thickness, aspect ratios, slot end hole size, no. of holes, are chosen for test. These specimen sizes are chosen to facilitate the measurements by using the same fixture for all the specimens. As boundary conditions for plate specimens are inner edge fixed and outer edge free. The FEA analysis is done on the ANSYS software and following results were obtain which are tabulated as follows, Case 1- For Variable Aspect ratio

TABLE 3.4.1 Result table for test specimen 1

\begin{tabular}{|c|c|c|c|c|}
\hline Specimen & Aspect ratio b/a & $\begin{array}{c}\text { Inner diameter in } \\
\text { mm }\end{array}$ & $\begin{array}{c}\text { Outer diameter } \\
\text { in mm }\end{array}$ & $\begin{array}{c}\text { Number of } \\
\text { holes or slots }\end{array}$ \\
\hline Plate 1 & 0.182 & 20 & 110 & 0 \\
\hline Natural Frequencies by FEA & 724.33 & 726 & 780.27 & 963.8 \\
\hline Plate 2 & 0.4 & 20 & 50 & 0 \\
\hline Natural Frequencies by FEA & 5484.0 & 5516.8 & 5529.5 & 6254.5 \\
\hline
\end{tabular}




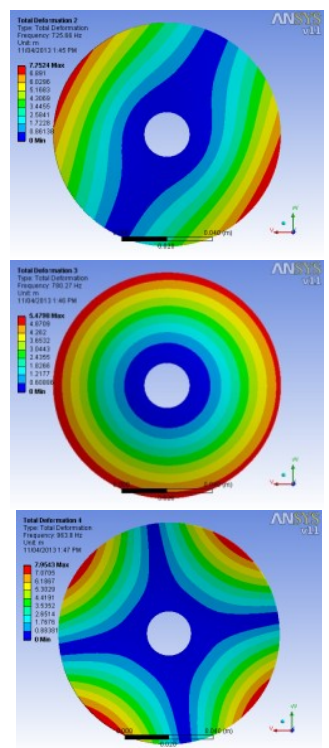

Fig 3.4.1 Mode shape for aspect ratio 0.182

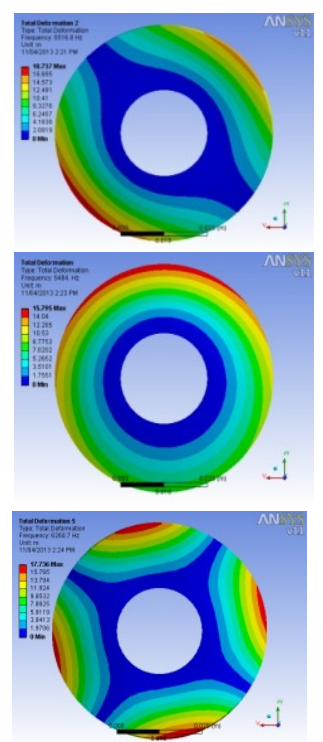

Fig 3.4.2 Mode shape for aspect ratio 0.4

Case 2- For Variable thickness

TABLE 3.4.2 Result table for test specimen 2

\begin{tabular}{|c|c|c|c|c|}
\hline Specimen & Aspect ratio b/a & $\begin{array}{c}\text { Inner diameter } \\
\text { in } \mathbf{~ m m}\end{array}$ & $\begin{array}{c}\text { Outer diameter } \\
\text { in } \mathbf{~ m m}\end{array}$ & $\begin{array}{c}\text { Thickness of } \\
\text { plates in } \mathbf{~ m m}\end{array}$ \\
\hline Plate 1 & 0.182 & 20 & 110 & 1.5 \\
\hline Natural Frequencies by FEA & 724.33 & 726 & 780.27 & 963.8 \\
\hline Plate 3 & 0.182 & 20 & 110 & 3 \\
\hline Natural Frequencies by FEA & 1443 & 1445.3 & 1561.3 & 1910.3 \\
\hline
\end{tabular}
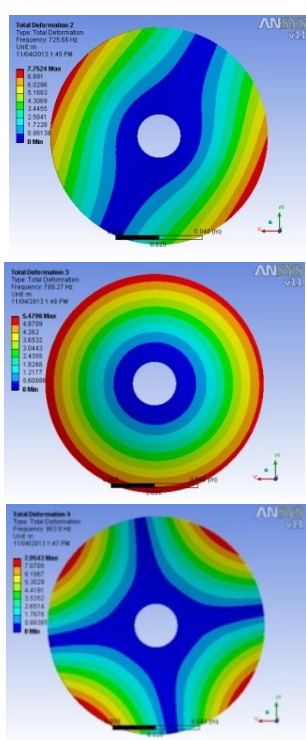

Fig 3.4.3 Mode shape for Thickness $1.5 \mathrm{~mm}$
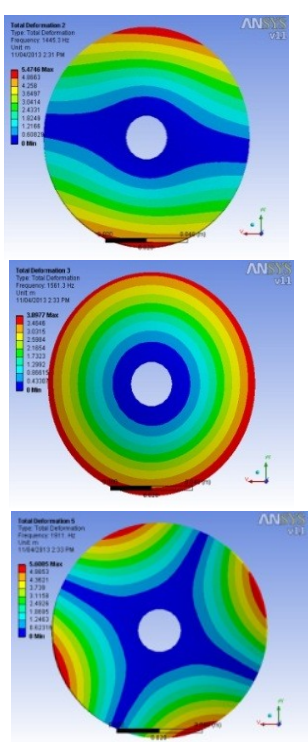

Fig 3.4.4 Mode shape for Thickness $3 \mathrm{~mm}$

Case 3 - For No. of Holes in plate

TABLE 3.4.3 Result table for test specimen 3

\begin{tabular}{|c|c|c|c|c|c|}
\hline Specimen & $\begin{array}{c}\text { Aspect ratio } \\
\text { b/a }\end{array}$ & $\begin{array}{c}\text { Inner } \\
\text { diameter in } \\
\mathbf{m m}\end{array}$ & $\begin{array}{c}\text { Outer } \\
\text { diameter in } \\
\mathbf{m m}\end{array}$ & $\begin{array}{c}\text { Number of } \\
\text { holes }\end{array}$ & $\begin{array}{c}\text { Dia. Of } \\
\text { holes in } \\
\text { mm }\end{array}$ \\
\hline Plate 1 & 0.182 & 20 & 110 & 0 & 0 \\
\hline $\begin{array}{c}\text { Natural Frequencies by } \\
\text { FEA }\end{array}$ & 724.33 & 726 & 780.27 & 963.8 & 965 \\
\hline Plate 4 & 0.182 & 20 & 110 & 9 & 10 \\
\hline $\begin{array}{c}\text { Natural Frequencies by } \\
\text { FEA }\end{array}$ & 594 & 594.68 & 640.34 & 787.41 & 788.10 \\
\hline
\end{tabular}




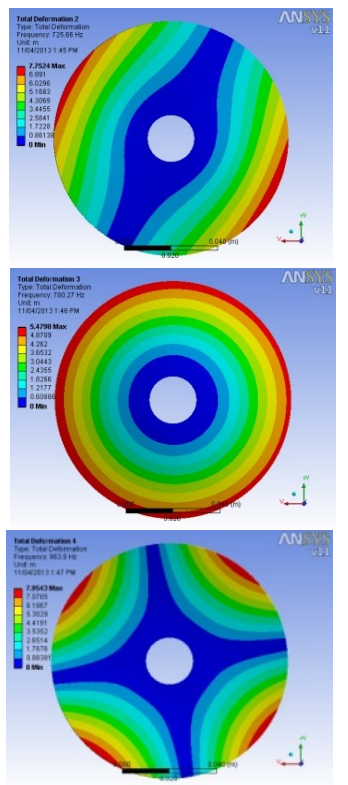

Fig 3.4.5 Mode shape for plates without holes
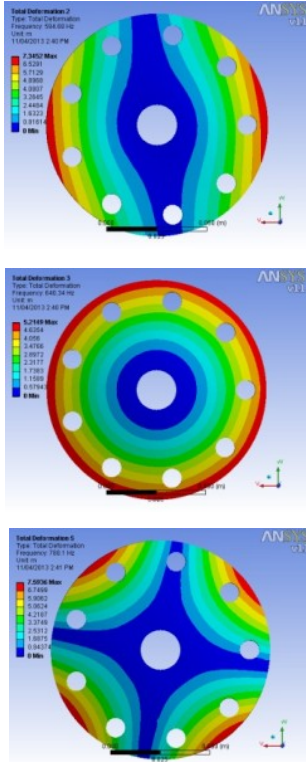

Fig 3.4.6 Mode shape for plates with 9 holes

Case 4- For Variable diameter of Holes in plate

TABLE 3.4.4 Result table for test specimen 4

\begin{tabular}{|c|c|c|c|c|c|}
\hline Specimen & $\begin{array}{c}\text { Aspect } \\
\text { ratio b/a }\end{array}$ & $\begin{array}{c}\text { Inner diameter } \\
\text { in } \mathbf{~ m m}\end{array}$ & $\begin{array}{c}\text { Outer diameter } \\
\text { in } \mathbf{~ m m}\end{array}$ & $\begin{array}{c}\text { Number } \\
\text { of holes }\end{array}$ & $\begin{array}{c}\text { Dia. Of } \\
\text { holes in } \mathbf{~ m m}\end{array}$ \\
\hline Plate 4 & 0.182 & 20 & 110 & 9 & 5 \\
\hline Natural Frequencies by FEA & 571.86 & 572.68 & 623.19 & 774.19 & 775.03 \\
\hline Plate 5 & 0.182 & 20 & 110 & 9 & 10 \\
\hline Natural Frequencies by FEA & 594 & 594.68 & 640.34 & 787.41 & 788.10 \\
\hline
\end{tabular}
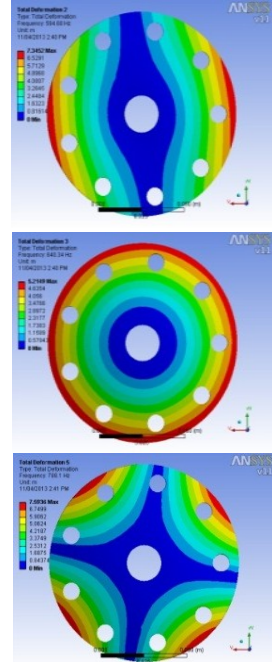
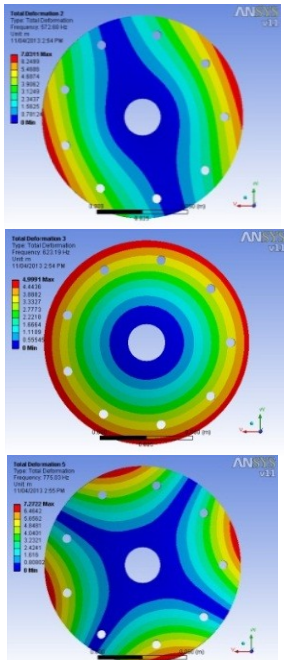

Fig 3.4.7 Mode shape for plates with 9 holes of $10 \mathrm{~mm} \& 5 \mathrm{~mm}$ diameter

Case 5- For No. of slots in plate

Table 3.4.5 Result table for test specimen 5

\begin{tabular}{|c|c|c|c|c|c|}
\hline Specimen & $\begin{array}{c}\text { Aspect } \\
\text { ratio b/a }\end{array}$ & $\begin{array}{c}\text { Inner } \\
\text { diameter in } \\
\mathbf{m m}\end{array}$ & $\begin{array}{c}\text { Outer diameter } \\
\text { in } \mathbf{~ m m}\end{array}$ & $\begin{array}{c}\text { Number of } \\
\text { slots of length } \\
\mathbf{1 7 . 5} \mathbf{~ m m} \text {. }\end{array}$ & $\begin{array}{c}\text { slot end } \\
\text { hole } \\
\text { dia.mm }\end{array}$ \\
\hline Plate 6 & 0.182 & 20 & 110 & 9 & 5 \\
\hline Natural Frequencies by FEA & 602 & 695 & 1014 & 1427 & 2311 \\
\hline Plate 7 & 0.182 & 20 & 110 & 10 & 5 \\
\hline Natural Frequencies by FEA & 851 & 953 & 1255 & 1677 & 1917 \\
\hline
\end{tabular}



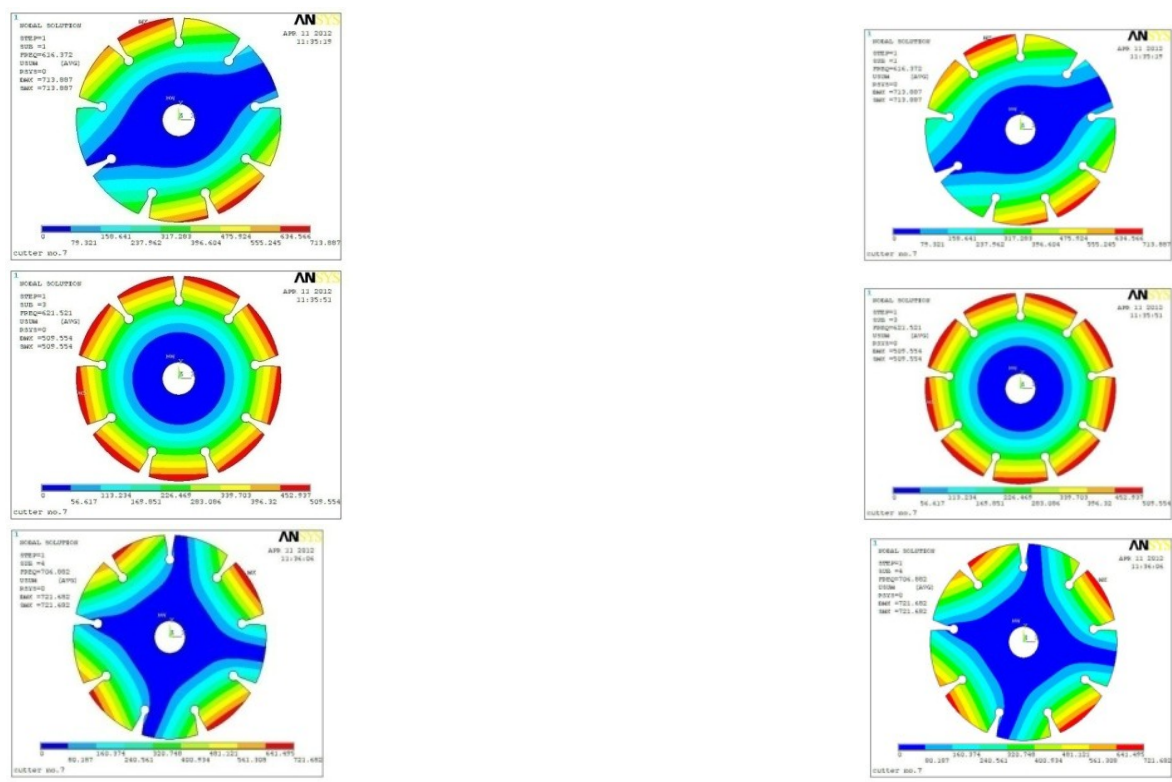

Fig. 3.4.8 Mode shape for plates with 9 radial slot $\&$ diff. slot end diameter

Case 6- For variable dia. of slot end in plate

Table 3.4.6 Result table for test specimen 6

\begin{tabular}{|c|c|c|c|c|c|}
\hline Specimen & $\begin{array}{c}\text { Aspect } \\
\text { ratio b/a }\end{array}$ & $\begin{array}{c}\text { Inner } \\
\text { diameter in } \\
\text { mm }\end{array}$ & $\begin{array}{c}\text { Outer diameter } \\
\text { in mm }\end{array}$ & $\begin{array}{c}\text { Number of slots } \\
\text { of length 17.5 } \\
\text { mm. }\end{array}$ & $\begin{array}{c}\text { slot end } \\
\text { hole dia.mm }\end{array}$ \\
\hline Plate 7 & 0.182 & 20 & 110 & 10 & 5 \\
\hline $\begin{array}{c}\text { Natural Frequencies } \\
\text { by FEA }\end{array}$ & 851 & 953 & 1255 & 1677 & 1917 \\
\hline Plate 8 & 0.182 & 20 & 110 & 10 & 10 \\
\hline $\begin{array}{c}\text { Natural Frequencies } \\
\text { by FEA }\end{array}$ & 828 & 909 & 1087 & 1316 & 1421 \\
\hline
\end{tabular}

V. Result And Discussion

On the basis of the FEA analysis by using the ANSYS software analysis of vibration characteristics of circular plates with free boundary condition but having different numbers of holes, aspect ratio, effect of radial slots/cutouts and with diff thickness of plate is done\& the following results are predicted.

Case 1- For Variable Aspect ratio

As the Aspect ratio is increases the natural frequency is increases. 100\% increment in the aspect ratio gives 648 $\%$ to $757 \%$ increase in natural frequency variable as per modes.

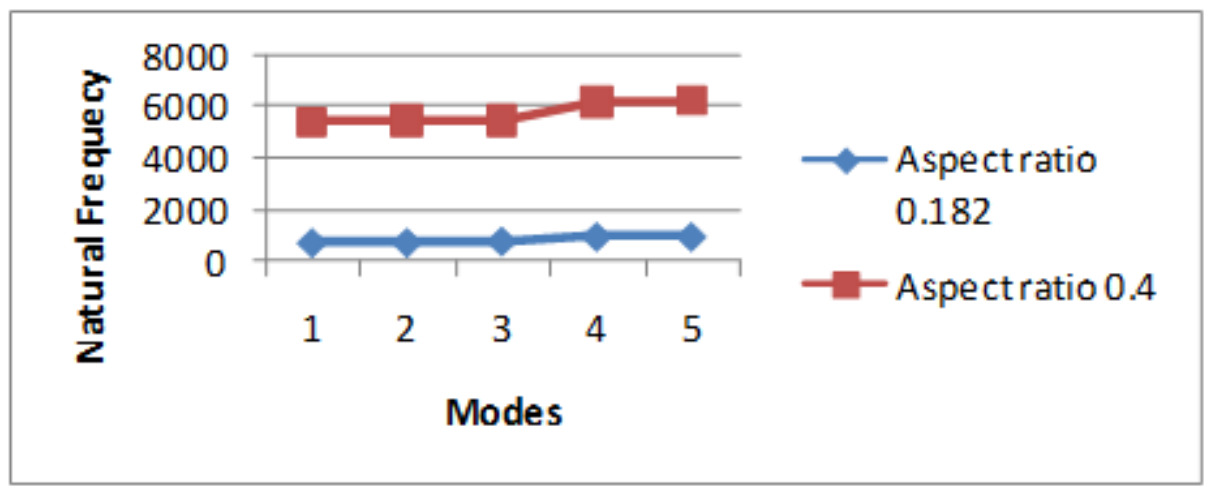

Fig 5.1 Comparison of natural frequency for Variable Aspect ratio

Case 2- For Variable thickness

As the thickness is increases the natural frequency is increases. $100 \%$ increment in the thickness gives $200 \%$ increase in natural frequency variable as per modes. 


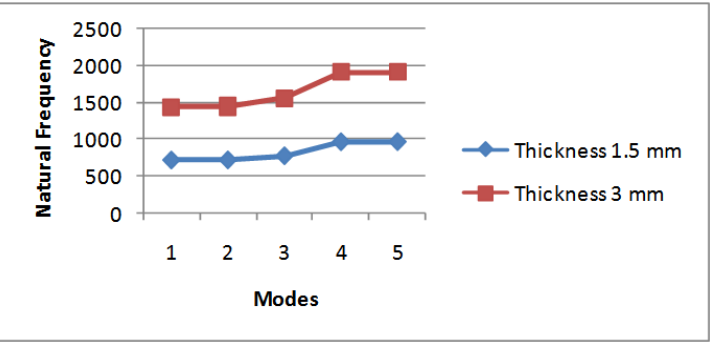

Fig 5.2 Comparison of natural frequency for Variable thickness

Case 3- For No. of Holes in plate

Natural frequency decreases if air cooling holes are added to circular annular plates. As the holes are introduced in the plate it reduces the natural frequency. Compare with the plate without holes the frequency is reduced by $122 \%$.

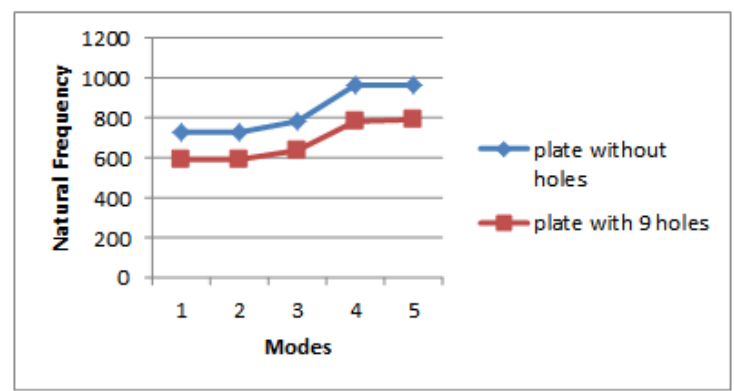

Fig 5.3 Comparison of natural frequency for No. of Holes in plate

Case 4- For Variable diameter of Holes in plate

Natural frequency decreases if air cooling holes are added to circular annular plates. Also as the diameter of the air cooling holes is changed the natural frequency is reduced by $103 \%$,

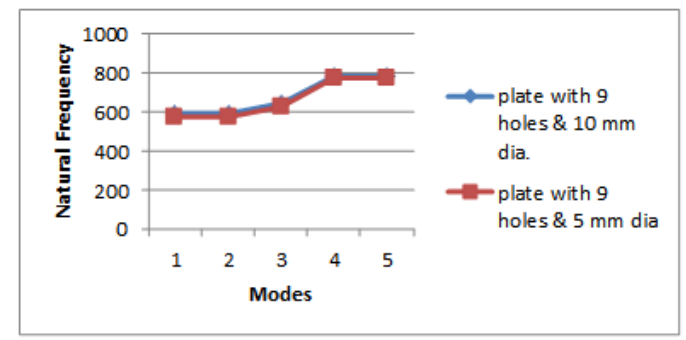

Fig 5.4 Comparison of natural frequency for Variable diameter of Holes in plate

Case 5- For No. of slots in plate

Natural frequency increases as the no. of radial slots increases. $10 \%$ change in the no. of radial slots gives $7 \%$ to $40 \%$ change in natural frequency variable as per modes.

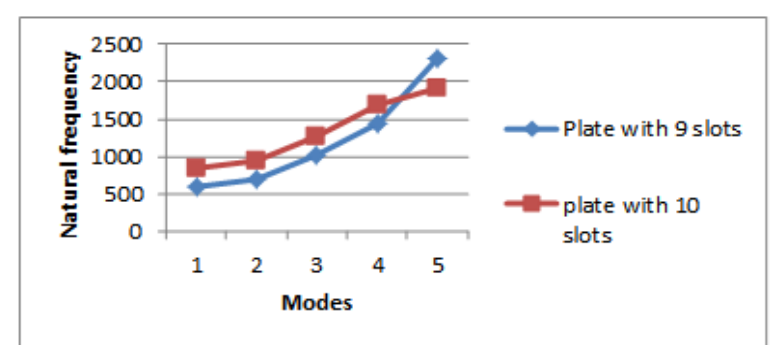

Fig 5.5 Comparison of natural frequency for No. of slots in plate 
Case 6- For variable diameter of slot end in plate

Natural frequency decreases as crack end hole diameter increases. 3 to $34 \%$ reductions in natural frequency is achieved by $100 \%$ enlargement of crack end whole diameter.

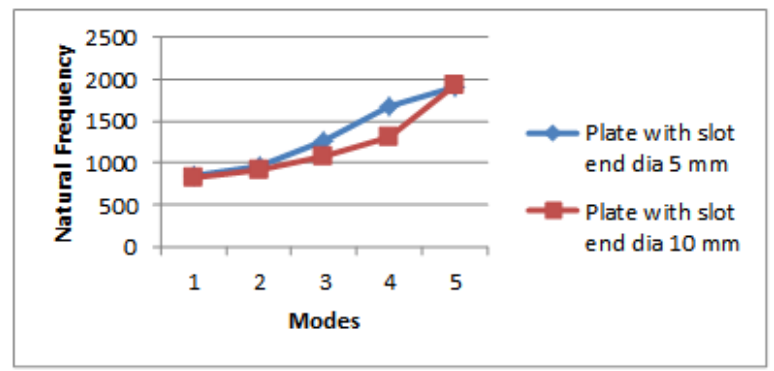

Fig 5.6 Comparison of natural frequency for variable diameter of slot end in plate

\section{Conclusion}

The main thrust of the work is towards the understanding of the vibration behavior of plates with diff conditions for circular saw blades and disc brake plates in static condition. Analysis of vibration characteristics of circular plates with free boundary condition but having different numbers of holes, aspect ratio, thickness and effect of radial slots/cutouts are done with the FEM analysis and the results are predicted. Depending on the various conditions the results are concluded.

Conclusion on various specimens for different conditions are obtain as, For variable Aspect ratio, As the Aspect ratio is increases the natural frequency is increases. For variable Thickness of plates, As the thickness is increases the natural frequency is increases. For Variable No. of Holes in plate, Natural frequency decreases if air cooling holes are added to circular annular plates. For Variable diameter of Holes in plate, As the diameter of the air cooling holes is changed the natural frequency is reduced. For No. of slots in plate, Natural frequency increases as the no. of radial slots increases. for variable dia. of slot end in plate, natural frequency decreases as crack end hole diameter increases.

\section{References}

[1] A.W. Leissa, The Shock and Vibration Digest (Plate vibration research, 1981).

[2] L. Cheng, et.al. Vibration analysis of annular-like plates, Journal of Sound and Vibration, vol. 262, pp. (2003), 1153-1170.

[3] Weisensel G. N, Natural Frequency Information for Circular and Annular Plates, Journal of Sound and Vibration,) vol. 133(l), (1989), 129-134.

[4] Wook Kang \& et.al, Approximate closed form solutions for free vibration of polar orthotropic circular plates, Journal of Applied Acoustics, vol. 66 (2005), 1162-1179.

[5] Z.H.Zhou et.al, Natural vibration of circular and annular thin plates by Hamiltonian approach, Journal of Sound and Vibration, vol.330, (2011), 1005-1017. 